Obstructive Lung Disease in Northern Sweden Studies. Respir Med 2003; 97: 115-122.

5 British Thoracic Society. Guidelines for the management of chronic obstructive pulmonary disease. Thorax 1997; 52: Suppl. 5, S1-S28.

6 Calverley PMA, MacNee W, Pride NB, Rennard SI, eds. Chronic Obstructive Pulmonary Disease. 2nd Edn. London, Arnold, 2003.

7 Mannino DM. COPD: epidemiology, prevalence, morbidity and mortality, and disease heterogeneity. Chest 2002; 121: Suppl. 5, 121S-126S.

8 US Surgeon General, ed. The Health Consequences of Smoking: Chronic Obstructive Lung Disease. Publ No. 8450205. Washington DC, USDHHS, 1984.

9 Mannino DM, Buist AS, Petty TL, Enright PL, Redd SC. Lung function mortality in the United States: data from the first National Health and Nutrition Examination Survey follow up study. Thorax 2003; 58: 388-393.

10 World Health Report 2002. Message from the DirectorGeneral, Dr GH Brundtland. Overview. Geneva, World Health Organization, 2002; pp. ix-xx.

11 World Health Report 2002. Message from the DirectorGeneral, Dr GH Brundtland. Quantifying selected major risks to health. Geneva, World Health Organization, 2002; pp. 68-76.

12 Trupin L, Earnest G, San Pedro M, et al. The occupational burden of chronic obstructive pulmonary disease. Eur Respir J 2003; 22: 462-469.

13 Ezzati M, Lopez AD. Estimates of global mortality attributable to smoking in 2000. Lancet 2003; 362: 847-852.

\title{
High prevalence of abnormal acid gastro-oesophageal reflux in idiopathic pulmonary fibrosis
}

\section{To the Editors:}

The role of gastro-oesophageal reflux in idiopathic pulmonary fibrosis (IPF) has been given little consideration in the literature, and RAGHU et al. [1] have made a significant contribution in this regard. However, if we examine their data in terms of attributable risk, the potential clinical impact of these findings becomes even clearer.

Several other reports have suggested a possible link between gastro-oesophageal reflux and IPF. A case-control study from 1976 determined the prevalence of reflux to be higher in 48 patients with IPF than in 270 age-matched controls with fibrosis of other aetiologies [2]. TOBIN et al. [3] previously published a smaller case-control study which identified that 16 out of $17(94 \%)$ patients with IPF compared with four out of eight $(50 \%)$ patients with interstitial lung disease due to other causes had abnormal acid exposure in the oesophagus. In 2005, PATTI et al. [4] determined the prevalence of gastrooesophageal reflux in IPF patients to be $66 \%$, with a third of those patients having no reflux symptoms.

In the current study, 46 patients with IPF not currently receiving proton pump inhibitor (PPI) therapy were compared with 133 asthmatics also not receiving PPI therapy. All patients were subjected to 24-h $\mathrm{pH}$-probe testing. The prevalence of abnormal acid exposure was 87 and $68 \%$ in IPF patients and asthmatics, respectively (statistically significant, $\mathrm{p}=0.014$ ). Thus, the odds of having IPF in those with abnormal acid exposure as compared to those without (odds ratio) is 3.19. The attributable risk percentage (ARP) calculated based on table 1, which was constructed using data from the study by RAGHU et al. [1], is $68.6 \%$. If we assume a causal relationship between reflux and IPF, then simply stated the ARP means that $68.6 \%$ of the cases of IPF in patients with abnormal acid exposure would not have occurred in the absence of exposure. The population
ARP is $49.8 \%$, which means that in the population of patients studied, almost half of IPF cases identified would not have occurred in the absence of abnormal acid exposure.

Unfortunately, the data presented by RAGHU et al. [1] also suggest that only $47 \%$ of patients with abnormal acid exposure experienced gastrointestinal symptoms, meaning that symptom-targeted therapy may not be effective. Given the relatively low cost of proton pump inhibitor therapy and low side-effect profile compared with other available therapies for idiopathic pulmonary fibrosis, these data suggest that at the very least treatment with a proton pump inhibitor should be strongly considered in patients with idiopathic pulmonary fibrosis until better data are available. The data presented by RAGHU et al. [1] also showed that 12 out of 19 patients on proton pump inhibitors still had abnormal results from $\mathrm{pH}$ probe studies. More research needs to be carried out regarding the association between reflux and idiopathic pulmonary fibrosis to determine whether even more aggressive therapies should be considered, should treatment with proton pump inhibitors fail to adequately treat reflux.

\begin{tabular}{lccc} 
TABLE 1 & $\begin{array}{l}\text { Frequency of gastro-oesophageal reflux in } \\
\text { patients with IPF and asthma }\end{array}$ \\
& IPF cases & Asthma controls & Totals \\
\hline GERD+ & 40 & 90 & 130 \\
GERD- & 6 & 43 & 49 \\
Totals & 46 & 133 & 179 \\
\hline & & \\
Data are presented as n. IPF: idiopathic pulmonary fibrosis; GERD: gastro- \\
oesophageal reflux disease; +: positive; -: negative.
\end{tabular}




\section{M.K. Han}

University of Michigan Health System, Ann Arbor, MI, USA.

\section{REFERENCES}

1 Raghu G, Freudenberger TD, Yang S, et al. High prevalence of abnormal gastro-oesophageal reflux in idiopathic pulmonary fibrosis. Eur Respir J 2006; 27: 136-142.

2 Mays EE, Dubois JJ, Hamilton GB. Pulmonary fibrosis associated with tracheobronchial aspiration. A study of the frequency of hiatal hernia and gastroesophageal reflux in interstitial pulmonary fibrosis of obscure etiology. Chest 1976; 69: 512-515.

3 Tobin RW, Pope CE 2nd, Pellegrini CA, Emonda MJ, Sillery J, Raghu G. Increased prevalence of gastroesophageal reflux in patients with idiopathic pulmonary fibrosis. Am J Respir Crit Care Med 1998; 158: 1804-1808.

4 Patti MC, Tedesco P, Golden J, et al. Idiopathic pulmonary fibrosis: how often is it really idiopathic. J Gastrointest Surg 2005; 9: 1053-1056.

DOI: 10.1183/09031936.06.00071806

\section{From the authors:}

We appreciate M.K. Han's interest in the results of our study [1] and for the extended analyses of our data by calculating the risk for the population with acid gastro-oesophageal reflux (GER) and idiopathic pulmonary fibrosis (IPF). While this interesting observation deserves further study, as emphasised, it is apparent that the calculated risk is based on the number of GER disease $+=130 /$ number of cases + controls $=179 \times(\mathrm{OR}-1)$ / $\mathrm{OR}=.498$. Since an effective treatment regimen to improve patient outcome is yet to be determined for IPF, M.K. Han argues for patients with IPF to be treated for acid GER.

It is important to reiterate that our study design was not intended to investigate the causal effect of acid GER in IPF. While further studies are needed to clarify this in the pathogenesis of IPF, we have recently reported that some patients with IPF stabilise with adequate control of acid GER [2]. Only a double-blind, placebo-controlled, randomised clinical trial, with use of proton pump inhibitors (PPIs), can determine the efficacy of PPI in the treatment for IPF. In designing clinical trials using other agents, it may also be important to stratify randomisation based on the use of PPI at baseline and during the study period.

As more investigators and clinicians are recognising the high association of acid GER in IPF, M.K. Han's suggestion to treat IPF patients empirically with PPI will undoubtedly be raised again. We believe it is imperative to pursue further studies to determine the role of acid GER in the pathogenesis of IPF, and to determine if suppression of acid GER by medical and/or surgical treatment prevents further progression of IPF and/or improves outcome measures for patients with IPF.

We would like to thank M.K. Han for supporting our concepts by further analyses of our data. Hopefully, well-designed prospective clinical studies will be undertaken in the near future and the results will confirm the provocative observations.

\section{G. Raghu}

University of Washington, Seattle, WA, USA.

\section{REFERENCES}

1 Raghu G, Freudenberger TD, Yang S, et al. High prevalence of abnormal acid gastro-oesophageal reflux in idiopathic pulmonary fibrosis. Eur Respir J 2006; 27: 136-142.

2 Raghu G, Yang ST, Spada C, Hayes J, Pellegrini CA. Sole treatment of acid gastroesophageal reflux in idiopathic pulmonary fibrosis. Chest 2006; 129: 794-800.

DOI: $10.1183 / 09031936.06 .00067306$

\section{Sandblasting jeans kills young people}

\section{To the Editors:}

At this year's annual congress of the Turkish Thoracic Society (TTS), a mini-symposium was devoted to the occurrence of silicosis in the textile sector in Turkey. Clinicians from four cities reported on a total of 35 subjects with silicosis: 20, 10, four and one cases from Erzurum, Izmir, Tokat and Diyarbakir, respectively [1-4]. Nearly all patients were young males in their early twenties or even younger. They had been employed, often as undeclared workers, for only a few years in small workshops where denim jeans undergo jet sandblasting to give them a "worn-in" appearance. This job involved working long hours under very poor hygiene conditions, without any serious respiratory protection, and often far away from home, e.g. in Istanbul.

As no thorough occupational history had been taken or because silicosis was not suspected in these "textile" workers, several patients had initially been misdiagnosed as having tuberculosis (or sarcoidosis). So, depressingly beautiful images of high-resolution computed tomography scans or lung biopsies were projected, showing textbook presentations of acute silicosis (alveolar lipoproteinosis) or accelerated silicosis.

Two patients had started sandblasting when they were aged 13 and $14 \mathrm{yrs}$; both worked little more than 3 yrs and they died within a year of diagnosis, aged 18 and 19 yrs.

These two instances of silicosis in jeans sandblasters had already been reported at the 2005 congresses of the TTS and the European Respiratory Society, and they have now been published [5] (except for the fatal outcome). The suspicion of an epidemic now appears to be verified: an informal poll of $\sim 30$ participants in the mini-symposium at the TTS yielded another 15 cases from various other places in Turkey. 